\title{
Early Experience Modifies the Postnatal Assembly of Autonomic Emotional Motor Circuits in Rats
}

\author{
J. Patrick Card, ${ }^{1}$ Pat Levitt, ${ }^{2}$ Maxim Gluhovsky, ${ }^{1}$ and Linda Rinaman ${ }^{1}$ \\ ${ }^{1}$ Department of Neuroscience, University of Pittsburgh, Pittsburgh, Pennsylvania 15260, and ${ }^{2}$ Vanderbilt Kennedy Center for Research on Human \\ Development and Department of Pharmacology, Vanderbilt University, Nashville, Tennessee 37202
}

\begin{abstract}
Rat pups that are repeatedly handled and separated from their dam exhibit altered adult behavioral, endocrine, and autonomic responses to stress, but the extent to which early handling and/or maternal separation $(\mathrm{H} / \mathrm{S})$ alters the development of circuits that underlie these responses is unknown. The present study tested the hypothesis that early $\mathrm{H} / \mathrm{S}$ alters the postnatal assembly of synapses within preautonomic emotional motor circuits. Circuit development was traced by synapse-dependent retrograde transneuronal transport of pseudorabies virus (PRV) from the stomach wall. Control and H/S rats were analyzed between postnatal day 6 (P6) and P10, a period of rapid synaptic assembly among preautonomic circuit components. Pups in H/S groups were removed from their dam daily for either 15 min or $3 \mathrm{~h}$ beginning on P1, and were injected with virus on P8 and perfused on P10. Quantitative analyses of primary and transsynaptic PRV immunolabeling confirmed an age-dependent assembly of hypothalamic, limbic, and cortical inputs to autonomic nuclei. Circuit assembly was significantly altered in $\mathrm{H} / \mathrm{S}$ pups, in which fewer neurons in the central amygdala, the bed nucleus of the stria terminalis, and visceral cortices were infected compared with age-matched controls. In contrast, $\mathrm{H} / \mathrm{S}$ did not alter the assembly of paraventricular hypothalamic inputs to gastric autonomic neurons. H/S-related reductions in limbic and cortical transneuronal infection were similar in pups exposed daily to $15 \mathrm{~min}$ or $3 \mathrm{~h}$ maternal separation. These findings support the view that environmental events during early postnatal life can influence the formation of neural circuits that provide limbic and cortical control over autonomic emotional motor output.
\end{abstract}

Key words: autonomic; emotion; gastric; gastrointestinal; hypothalamus; limbic; stress; postnatal development; pseudorabies virus; maternal separation; transneuronal tracing

\section{Introduction}

Hebb (1949) proposed that circuit activity influences the strength of synaptic associations among neural circuit components. Subsequent validation of this hypothesis has come from a large body of literature demonstrating dynamic synaptic plasticity within the developing and mature CNS (Andersen, 2003). For example, classical conditioning involves synaptic strengthening in the cerebellum and amygdala in response to repeated pairings of previously unrelated sensory stimuli (Kim and Thompson, 1997; Medina et al., 2002). Similarly, activity-dependent plasticity of hippocampal circuits plays a critical role in learning and memory (Braunewell and Manahan-Vaughan, 2001; Debanne et al., 2003), and specific patterns of sensory experience shape the development of circuit connections within the neocortex (Fox, 2002; Nakahara et al., 2004; Bence and Levelt, 2005).

Despite abundant evidence that synaptic circuits are modifi-

Received June 8, 2005; revised Aug. 17, 2005; accepted Aug. 19, 2005.

This work was supported by The John D. and Catherine T. MacArthur Foundation Research Network on Early Experience and Brain Development and by National Institutes of Health Grant MH59911. We thank Dr. Thomas Koehnle for his statistical expertise and assistance with data analysis and Dr. Lynn Enquist for providing high-titer viral stocks.

Correspondence should be addressed to Dr. Linda Rinaman, Department of Neuroscience, 446 Crawford Hall, University of Pittsburgh, Pittsburgh, PA 15260. E-mail: rinaman@pitt.edu.

D0I:10.1523/JNEUROSCI.2345-05.2005

Copyright $\odot 2005$ Society for Neuroscience $\quad$ 0270-6474/05/259102-10\$15.00/0 able, the idea that early life experience can produce long-lasting changes in circuits that underlie emotional/affective behavior is less well documented. Animal models have provided compelling evidence that early postnatal experience can produce life-long changes in emotional responsiveness and stress reactivity. For example, handling and/or maternal separation $(\mathrm{H} / \mathrm{S})$ of rat pups during the first 2 weeks of life modifies their adult behavioral and physiological responses to stress (Plotsky and Meaney, 1993; Francis et al., 1999; Ladd et al., 2000; Heim and Nemeroff, 2001; Meaney, 2001; Pryce et al., 2001; Coutinho et al., 2002). Daily handling coupled with brief periods (i.e., $3-15 \mathrm{~min}$ ) of maternal separation leads to decreased signs of anxiety and stress reactivity exhibited in adulthood, whereas daily handling coupled with more lengthy periods (i.e., $3 \mathrm{~h}$ ) of maternal separation correlates with increased anxiety and stress reactivity. The effects of early life experience on adult stress responsiveness are accompanied by long-lasting changes in neurotransmitter mRNA expression and content, glucocorticoid receptor expression and gene methylation patterns, and neurotransmitter receptor levels in brain regions that mediate behavioral and physiological responses to stress (Plotsky and Meaney, 1993; Francis et al., 1999; Ladd et al., 2000; Meaney, 2001; Pryce et al., 2001; Coutinho et al., 2002; Weaver et al., 2004).

Autonomic motor circuits regulate visceral responses to stress and emotionally evocative stimuli. Central components of these 


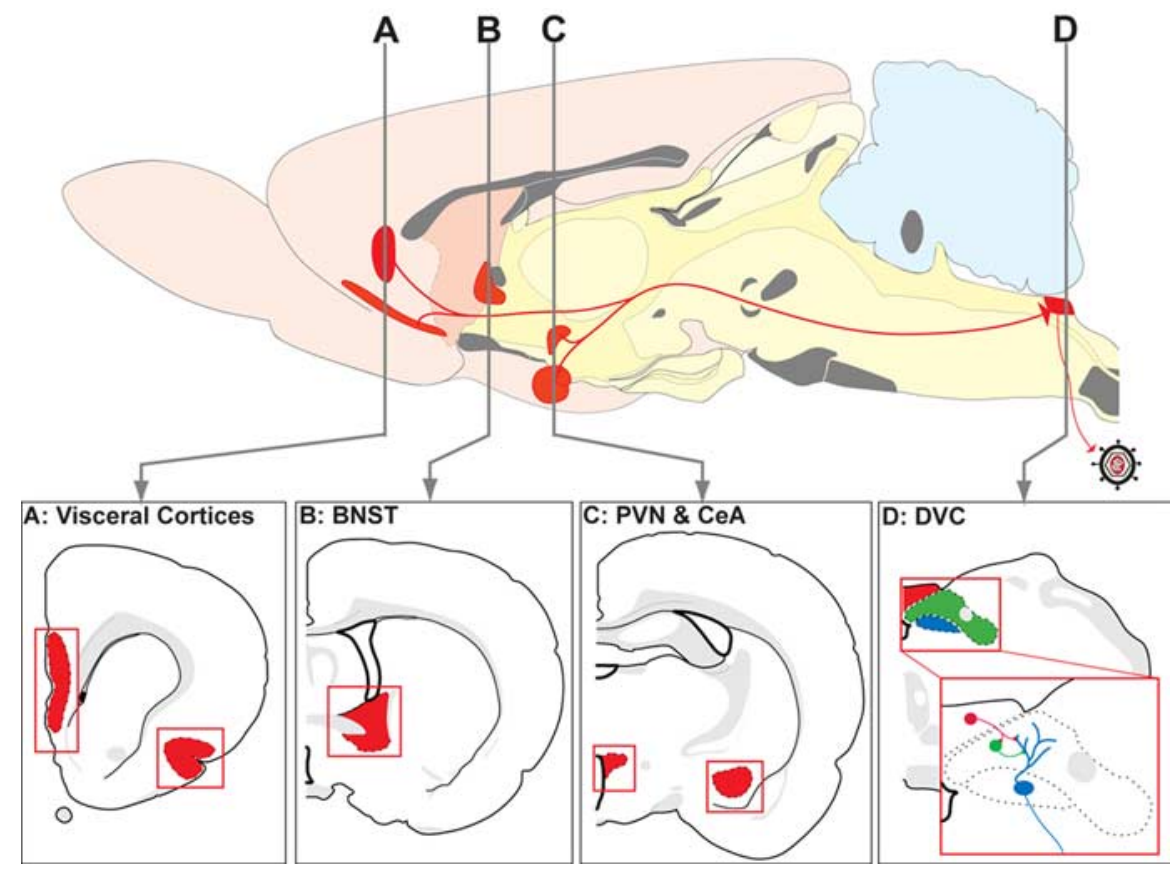

Figure 1. The routes of viral transport and regions subjected to quantitative analysis of the number of transneuronally infected neurons are illustrated. Previous studies in neonates and adult rats have demonstrated that injection of PRV-Bartha into the ventral wall of the stomach results in reproducible retrograde transneuronal infection of CNS neurons. Retrograde infection through the vagus nerve produces a first-order infection of parasympathetic vagal motor neurons within the DMV (D; blue). Replication and retrograde transneuronal passage of virus leads to the sequential infection of synaptically linked neurons in the adjacent NST ( $\boldsymbol{D}$; green) and AP (D; red). At longer survival intervals, virus passes transneuronally from the DVC to infect neurons in higher regions of the neuraxis. The present analysis focused on the hypothalamic PVN $(\boldsymbol{C})$, the CeA $(\boldsymbol{C})$, the BNST (B), and visceral cortices [insular cortex (IC) and medial prefrontal cortex (mPFC) (prelimbic and infralimbic)] (A). These areas are highlighted in red in the sagittal and coronal schematics, modified from Swanson (1998).

emotional motor circuits include hypothalamic and limbic forebrain preautonomic nuclei that provide direct and powerful modulatory control over sympathetic and parasympathetic outflow to the viscera. Previous work using transneuronal transport of pseudorabies virus (PRV) in developing rats demonstrated differential timing of hypothalamic and limbic forebrain synaptic inputs to autonomic neurons during the first 1-2 weeks postnatal (Rinaman et al., 1999, 2000). This neuroanatomical assay distinguishes the mere presence of developing axons within a target region from the formation of synapses that are necessary for transneuronal transport of PRV (Rinaman et al., 2000). We hypothesized that repeated H/S of rat pups during early postnatal life might alter the developmental assembly of these central autonomic circuits, thereby providing a potential structural correlate for early experience-dependent effects on later responsiveness to emotionally evocative stimuli. The H/S paradigm used in this work was modeled after the classic Plotsky and Meaney (1993) experimental approach, which revealed a sensitive period of postnatal development during which repeated H/S elicits persistent changes in stress responsiveness and emotionality.

\section{Materials and Methods}

Animals

Experimental protocols were approved by the University of Pittsburgh Institutional Animal Care and Use Committee and conformed to regulations stipulated in the National Institutes of Health Guide for the Care and Use of Laboratory Animals. Pregnant multiparous Sprague Dawley rats purchased from Zivic-Miller (Zelienople, PA) were used in all experiments. Pregnant females entered the biosafety level 2 (BSL-2) laboratory on approximately day 16 of gestation, where they were housed under controlled photoperiod ( $12 \mathrm{~h}$ light/dark cycle; lights on at 7:00 A.M.) and temperature $\left(20-22^{\circ} \mathrm{C}\right)$ in individual opaque polyethylene cages containing Sanicel bedding, with free access to food and water. Bedding was not changed during the course of experiments. Cages were checked for pups several times a day to verify the date of parturition, designated postnatal day $0(\mathrm{P} 0)$. Each litter was culled to a maximum of 10 male and female pups on $\mathrm{P} 0$ or P1. Nine litters of pups were used. Only one litter at a time was housed in the BSL-2 laboratory, and care was taken to minimize extraneous disturbances during each experiment. These procedures are consistent with those used in other studies of the effects of maternal care on developing rats (Champagne et al., 2003).

\section{Experimental design}

The handling and maternal separation paradigm was modeled after that described by Plotsky and Meaney (1993). All pups within a litter received the same treatment. Pups in nonhandled/nonseparated (NH/NS) control litters remained with their dam continuously, except during viral inoculation surgery (described below). Pups in H/S experimental litters were briefly handled each day at $\sim 10: 00$ A.M., beginning on $\mathrm{P} 1$, to separate them from their dam for either $15 \mathrm{~min}$ or for $3 \mathrm{~h}$. For this purpose, the entire litter of pups was moved together with a handful of home cage bedding to a small box contained within an incubator in the BSL-2 laboratory. Latex gloves were worn by the investigator when handling pups. The incubator was located in the same room $\sim 3$ feet away from the home cage, where the dam remained. Incubator temperature $\left(37^{\circ} \mathrm{C}\right)$ and humidity $(40-50 \%)$ were controlled to reproduce

conditions in the home cage. The artificial nest (i.e., small box with home cage bedding) kept the pups in close contact throughout the period of maternal separation, during which time the laboratory remained quiet and undisturbed. Pups and bedding were returned simultaneously to the home cage at the end of each separation period. The H/S regimen in each litter was repeated daily until pups were killed by perfusion fixation (described below).

\section{PRV inoculation}

Rat pups were subjected to viral inoculation surgery on $\mathrm{P} 4$ or P8. All pups inoculated on $\mathrm{P} 4$ were NH/NS controls. Those inoculated on P8 included pups from the NH/NS group, the $15 \mathrm{~min} \mathrm{H/S}$ group, and the $3 \mathrm{~h} \mathrm{H} / \mathrm{S}$ group. Pups in the control and $15 \mathrm{~min} \mathrm{H/S}$ groups were removed individually from the home cage for surgery and were returned $\sim 15-20 \mathrm{~min}$ later, immediately after recovering from anesthesia. For pups in the $3 \mathrm{~h}$ $\mathrm{H} / \mathrm{S}$ group, $\mathrm{PRV}$ inoculation was conducted during the normal period of maternal separation.

Pups were weighed and then anesthetized by halothane inhalation $(2 \%$ in oxygen). The stomach was exposed by laparotomy. The ventral wall of the milk-filled stomach was easily visualized through the thin and relatively transparent abdominal muscles, which were not incised. With the aid of a surgical microscope, a $5.0 \mu \mathrm{l}$ Hamilton syringe, filled with the Bartha strain of PRV (Bartha, 1961) and equipped with a fine glass tip, was inserted tangentially through the abdominal muscles into the ventral stomach wall, where a total volume of $1.0 \mu \mathrm{l}$ of virus $\left(10^{8} \mathrm{pfu} / \mathrm{ml}\right)$ was distributed at two or three injection sites. The abdominal skin incision was closed with silk sutures and cleaned with saline. Pups were placed on a heating pad until they regained consciousness and were then returned to their littermates in the incubator ( $3 \mathrm{~h} \mathrm{H} / \mathrm{S}$ group) or home cage (control NH/NS and $15 \mathrm{~min} \mathrm{H/S} \mathrm{groups).}$

\section{Perfusion and histology}

After postinoculation intervals of 63-66 h, pups were anesthetized by intraperitoneal injection of sodium pentobarbital (Nembutal; $1.0 \mathrm{mg} / \mathrm{g}$ body weight) and perfused transcardially with a brief saline rinse fol- 
lowed by $50 \mathrm{ml}$ of $4 \%$ paraformaldehyde in $0.1 \mathrm{M}$ sodium phosphate buffer, $\mathrm{pH}$ 7.2. Brains were postfixed in situ for $18-24 \mathrm{~h}$ at $4^{\circ} \mathrm{C}$, and then removed from the skull and cryoprotected for $24-48 \mathrm{~h}$ in $20 \%$ aqueous sucrose. Brains were sectioned serially in the coronal plane at $40 \mu \mathrm{m}$ using a sliding microtome (Leica, Nussloch, Germany) fitted with a freezing stage (Physitemp, Clifton, NJ). Brain sections from the spinomedullary junction through the prefrontal cortex rostral to the corpus callosum were collected serially in four adjacent sets and stored at $-20^{\circ} \mathrm{C}$ in cryopreservant (Watson et al., 1986).

\section{Immunocytochemistry}

Tissue sections were rinsed for $1 \mathrm{~h}$ in buffer before immunocytochemical procedures. Antisera were diluted in buffer containing $0.3 \%$ Triton X-100 and 1\% normal donkey serum. Sections were processed for immunoperoxidase localization of transported virus using a rabbit polyclonal anti-PRV antiserum (PRV133; 1:20,000; provided by Dr. Lynn Enquist, Princeton University, Princeton, NJ), biotinylated goat antirabbit IgG (1:500; Jackson ImmunoResearch, West Grove, PA), and Vectastain Elite $\mathrm{ABC}$ immunoperoxidase reagents (Vector Laboratories, Burlingame, CA). Sections were incubated in diaminobenzidine and $\mathrm{H}_{2} \mathrm{O}_{2}$ to generate a brown reaction product in PRV-infected cells. Immunolabeled sections were mounted onto Superfrost Plus microscope slides (Fisher Scientific, Pittsburgh, PA), dehydrated in graded alcohols, cleared in xylene, and coverslipped in resin.

\section{Microscopic analysis}

Hindbrain tissue sections from each pup were initially examined to determine the presence and extent of infection in the caudal medullary dorsal vagal complex (DVC), comprising the dorsal motor nucleus of the vagus (DMV), nucleus of the solitary tract (NST), and area postrema (AP). Based on this initial examination, cases were classified as having met criteria for subsequent analysis or were eliminated from the study. The inclusion criterion was based on the known temporal progression of infection through the DVC to the forebrain after PRV inoculation of the ventral stomach wall in mature and developing rats (Rinaman et al., 1999, 2000). Initial retrograde infection of preganglionic gastric vagal motor neurons in the DMV is followed by the sequential transneuronal infection of presynaptic neurons in the NST and AP (Fig. 1). Infection of forebrain neurons in adult and developing rats reliably occurs coincident with infection of substantial numbers of neurons in the AP (Rinaman et al., 1999, 2000). In each experimental case, three medullary tissue sections sampling the rostrocaudal extent of the AP were analyzed using a $40 \times$ microscope objective, and the total number of infected AP neurons was recorded. The minimum inclusion criterion for cases to undergo additional analysis was the presence of at least 500 infected AP neurons. The goal of this screening process was to ensure adequate opportunity for transneuronal infection of forebrain neurons, and to control for experimental variability in the onset and extent of central PRV infection related to differences in viral uptake and transport from the peripheral injection sites.

Investigators were blinded to the age and treatment group of animals, thereby eliminating potential bias in the quantitative analysis of transneuronal forebrain infection. The forebrain regions subjected to quantitative analysis are arranged in complex subdivisions and occupy long linear extents of the CNS. Thus, the strategies described below were followed to ensure thorough and comparable sampling of each cell group across cases.

Paraventricular hypothalamic nucleus. The paraventricular hypothalamic nucleus (PVN) is a heterogeneous nucleus comprising multiple functionally distinct subdivisions (Armstrong et al., 1980; Swanson and Kuypers, 1980; Kiss et al., 1991). In each case, three coronal sections were analyzed that sampled the four PVN subfields containing preautonomic neurons: the anterior, medial, dorsal, and lateral parvocellular divisions.

Bed nucleus of the stria terminalis. Like the PVN, the bed nucleus of the stria terminalis (BNST) comprises distinct subfields that are projectionspecific and phenotypically distinct (Ju and Swanson, 1989; Ju et al., 1989). Six coronal sections from each case were analyzed, and these sections sampled cytoarchitectonically distinct subdivisions of the BNST throughout their rostrocaudal extent. These included the lateral subdi-
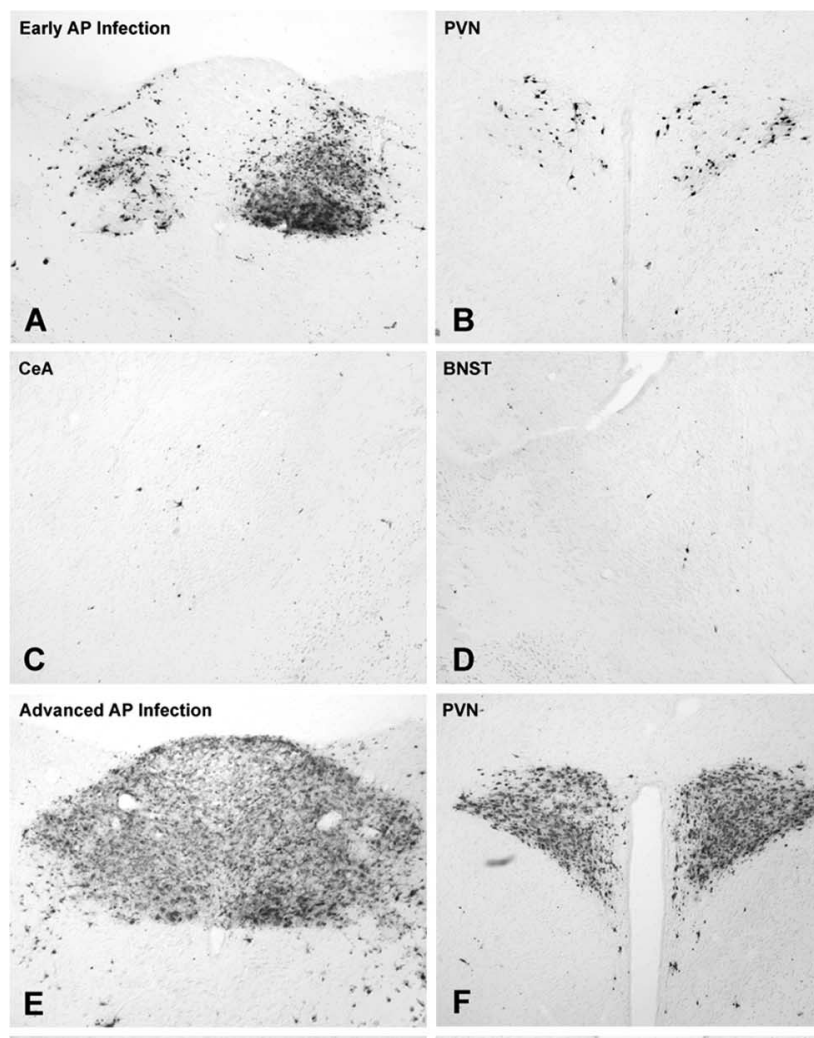

\section{D}

\section{B}

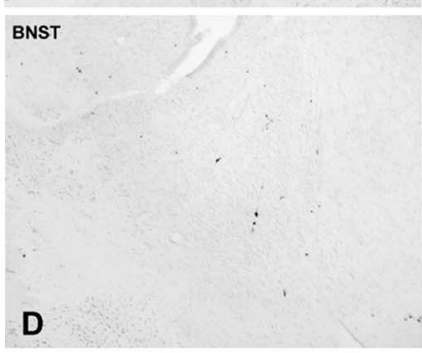

PVN-

CeA

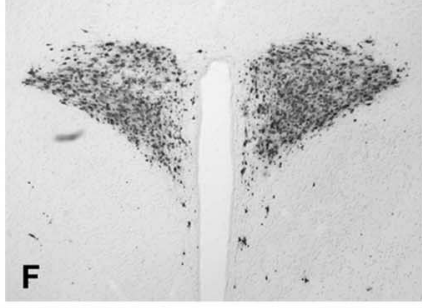

BNST

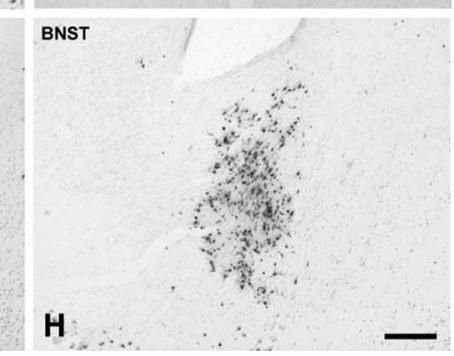

H

Figure 2. Immunocytochemical localization of PRV-positive neurons in control NH/NS rat pups injected with virus on P8 and killed after 63-66 h, on P10. The magnitude of forebrain infection (PVN, BNST, CeA) in individual cases correlated with the extent of infection in the AP (Table 2). Forebrain infection was sparse in cases that exhibited robust infection of the left DMV and NST but only scattered infection of AP $(\boldsymbol{A}-\boldsymbol{D})$. In contrast, extensive infection of neurons in the PVN, BNST, and CeA invariably accompanied extensive AP infection $(\boldsymbol{E}-\boldsymbol{H})$. Scale bar: (in $\boldsymbol{H}$ ) $\boldsymbol{A}-\boldsymbol{H}, 100 \mu \mathrm{m}$. See Figure 1 for regional schematics.

vision dorsal to the anterior commissure, containing the oval subnucleus in which preautonomic neurons are located, and the ventrolateral subdivision below the commissure, including the fusiform nucleus.

Central nucleus of the amygdala. Similar to the PVN and BNST, the central nucleus of the amygdala (CeA) contains distinct subdivisions (McDonald, 1982; Cassell et al., 1986). The medial subdivision of the CeA gives rise to efferent projections that target the DVC and other CNS regions. Two additional prominent subdivisions, the lateral and capsular subfields, provide presynaptic input to the medial CeA. Analysis of nine coronal sections from each experimental case was required to thoroughly sample the CeA.

Visceral cortices. The infralimbic (IL), prelimbic (PL), and insular (IN) cortices influence autonomic function and are commonly described as the "visceral motor cortex" (Saper, 2004). The IL/PL subdivisions of the medial prefrontal cortex are contained within a relatively circumscribed area that was effectively sampled by analysis of five coronal sections in each experimental case. The IN cortex occupies a long linear trajectory that required analysis of 12 coronal sections in each case.

Tissue sections were analyzed using a light microscopic image analysis system (Simple PCI; Compix Imaging Systems, Cranberry Township, 


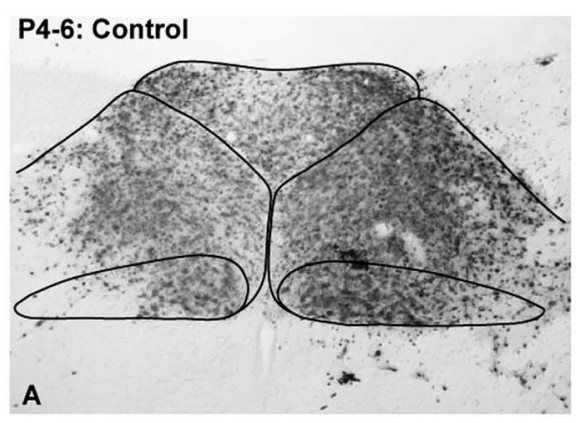

P8-10: 15 Minute Separation

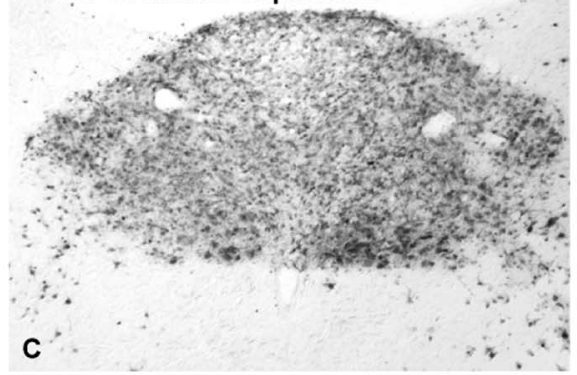

P8-10: Control

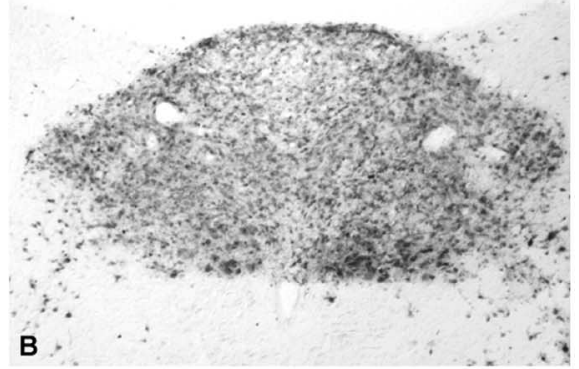

P8-10: 3 Hour Separation

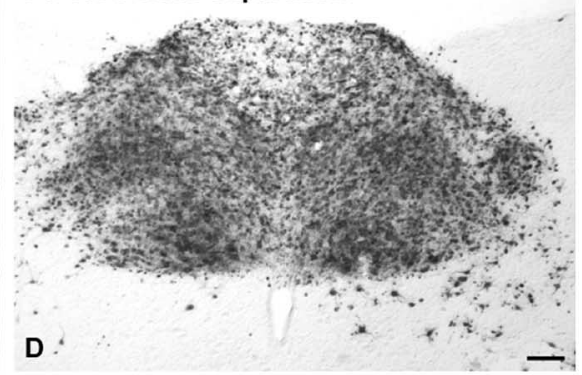

Figure 3. Inclusion criteria for the quantitative analysis of transneuronal infection of forebrain cell groups were based on the extent of infection in the AP. The borders of the three areas composing the DVC (i.e., DMV, NST, and AP) are demarcated (A) (see also Fig. 1). Rat pups included in quantitative analyses exhibited dense bilateral infection of the DVC, including a minimum of 500 infected AP neurons. $\boldsymbol{A}-\boldsymbol{D}$, Typical DVC infection in representative cases from each of the four experimental groups. Scale bar: (in D) $\boldsymbol{A}-\boldsymbol{D}, 100 \mu \mathrm{m}$. See Figure 1 for regional schematics.

Table 1. Counts of transneuronally infected neurons by age, treatment group, and brain region

\begin{tabular}{llcccccc}
\hline & \multicolumn{7}{l}{ Brain region } \\
\cline { 2 - 7 } Age, treatment $(n)$ & AP & PVN & BNST & CeA $_{m}$ & CeA $_{I}$ & Ctx-IN & Ctx-PL/IL \\
\hline P4-P6, control (5) & $1016 \pm 136^{A}$ & $574 \pm 117^{A}$ & $20 \pm 6^{A}$ & $60 \pm 31^{A}$ & $4 \pm 2^{A}$ & $0 \pm 0^{A}$ & $0 \pm 0^{A}$ \\
P8-P10, control (5) & $1496 \pm 299^{A}$ & $1739 \pm 430^{B}$ & $1227 \pm 275^{B}$ & $1295 \pm 214^{B}$ & $127 \pm 44^{B}$ & $75 \pm 22^{B}$ & $37 \pm 13^{B}$ \\
P8-P10, 15 min (8) & $1037 \pm 93^{A}$ & $863 \pm 103^{A, B}$ & $227 \pm 36^{C}$ & $246 \pm 34^{C}$ & $16 \pm 2^{C}$ & $6 \pm 2^{B}$ & $8 \pm 2^{C}$ \\
P8-P10,3 h (8) & $881 \pm 36^{A}$ & $842 \pm 53^{A, B}$ & $277 \pm 43^{C}$ & $233 \pm 28^{C}$ & $13 \pm 3^{C}$ & $11 \pm 4^{B}$ & $7 \pm 4^{B, C}$ \\
\hline
\end{tabular}

Values represent raw cell counts (group mean $\pm \mathrm{SE}$ ). Within each brain region, values with different superscript letters (i.e., $A, B$, or $C$ ) are significantly different $(p<0.05)$. Statistical comparisons were performed on log-transformed data that met assumptions of normality and homoscedasticity (see Results). CeA ${ }_{m}$, Medial CeA; CeA, lateral CeA; Ctx, cortex; IN, insular; PL/IL, prelimbic/infralimbic.

\section{Results}

Transneuronal infection of autonomic and preautonomic brainstem neurons

The extent of neural infection within the DMV, NST, and AP was variable across cases within each age and treatment group. PRV-immunopositive neurons were present within the DMV in all rats. DMV neural infection was always more prominent on the left side, where preganglionic vagal motor neurons projecting to postganglionic neurons within the ventral stomach wall are located (Shapiro and Miselis, 1985; Rinaman et al., 1999) (Figs. $2,3)$. The NST contained infected secondorder preautonomic neurons in every case examined. However, there were cases in which relatively few or no AP neurons were infected (Fig. 2A). AP neurons synapse on second-order NST neurons, which synapse on preganglionic DMV motor neurons (Fig. 1D). Only a subset of rat pups $(n=26)$ met the inclusion criterion of at least 500 infected AP neurons required for additional quantitative analysis of transneuronal forebrain infection. Five control pups from three litters injected with virus on $\mathrm{P} 4$ met this criterion (Fig. 3A), as did 21 pups from six litters injected with virus on P8. Within the P8 group, five pups were controls, eight were from the $15 \mathrm{~min}$ treatment group, and eight were from the $3 \mathrm{~h}$ treatment group (Fig. $3 B-D$ ). ANOVA revealed that the number of infected AP neurons across these 26 selected cases (Table 1) did not vary significantly as a factor of either age $\left(F_{(1,24)}=0.072 ; p=0.79\right)$ or treatment group $\left(F_{(2,23)}=1.52 ; p=0.24\right)$.

Infected neurons were present in additional preautonomic brainstem regions in

PA) with mapping and cell-counting capabilities. The external border of each tissue section and other landmarks (e.g., ventricles and prominent white matter fiber tracts such as the corpus callosum and anterior commissure) were mapped at low magnification using a $5 \times$ objective. Each region of interest (ROI) was sampled using a $40 \times$ objective and the location of each PRV-immunopositive cell was marked. Distinct markers were used for cells in different subdivisions of the same nucleus (e.g., four PVN subdivisions, two CeA subdivisions) to allow quantitative assessment of total and subregional neural infection within each area.

\section{Data analysis}

Raw counts of labeled neurons within the AP and each forebrain ROI were combined by age and treatment group to obtain group mean \pm $\mathrm{SE}$ values. Raw cell count values did not meet assumptions of normality and homoscedasticity (see Results); thus, cell count values were log transformed to meet these assumptions before statistical analyses. Transformed data were analyzed using ANOVA or ANCOVA (with AP count as covariate) to reveal significant main effects of age or treatment group on neural infection within each forebrain region of interest. When significant overall effects of age or treatment group were found, ANOVAs and ANCOVAs were followed up with post hoc protected $t$ tests with Bonferroni's adjustment for multiple comparisons. Differences were considered statistically significant when $p<0.05$. all 26 cases selected for additional analysis. These regions included the caudal raphe (obscurus, pallidus), paramedian reticular nucleus, caudal and rostral ventrolateral medulla, subceruleus nucleus, Barrington's nucleus, pedunculopontine tegmental nucleus, and ventrolateral periaqueductal gray (data not shown), consistent with two previous reports from our laboratory (Rinaman et al., 1999, 2000). No obvious age- or treatment-related differences were noted in the distribution of infected brainstem neurons. Spinal-cord labeling was not analyzed in the present study.

\section{Transneuronal forebrain labeling in control rat pups}

Covariation of forebrain labeling with AP labeling

Significant positive correlations were found between the number of infected AP neurons and the number of infected neurons in the PVN, BNST, and medial CeA in NH/NS control rat pups in both age groups (Table 2). Thus, the extent of AP infection in each animal provided a reliable covariate for examining the effect of age on transneuronal forebrain infection within each region by ANCOVA. The ability to normalize hypothalamic and limbic forebrain infection to AP infection reduced the potential impact of variable viral transport from peripheral injection sites on the 
Table 2. Simple regression analysis of the relationship between the number of infected AP neurons and the number of infected forebrain neurons in control rats from both age groups

\begin{tabular}{lllllll}
\hline & \multicolumn{2}{l}{ Forebrain region } \\
\cline { 2 - 6 } Age $(n)$ & PVN & BNST & $\mathrm{CeA}_{\mathrm{m}}$ & $\mathrm{CeA}$ & Ctx-IN & Ctx-PL/IL \\
\hline P4-P6 (5) & $0.982^{*}$ & $0.866^{*}$ & $0.960^{*}$ & $0.786^{\mathrm{ns}}$ & - & - \\
P8-P10 (5) & $0.968^{*}$ & $0.947^{*}$ & $0.950^{*}$ & $0.948^{*}$ & $0.949^{*}$ & $0.893^{*}$ \\
\hline
\end{tabular}

Values presented are correlation coefficients. Regression analyses were performed on log-transformed data that met assumptions of normality and homoscedasticity (see Results). —, No infection; CeA $m_{m}$, medial CeA; CeA, lateral CeA; Ctx, cortex; IN, insular; PL/IL, prelimbic/infralimbic.

*Statistically significant $(p<0.05)$; ns, not significant $(p>0.05)$.

central distribution and the extent of transneuronal viral transport among individual cases.

\section{$P V N$}

PRV-immunopositive neurons were present bilaterally in the anterior, dorsal, medial, and posterior parvocellular subdivisions of the PVN in NH/NS control rat pups from both age groups (Figs. $4,5)$. ANCOVA revealed a significant effect of age on the number of transneuronally infected PVN neurons in control rats $\left(F_{(1,8)}=\right.$ $16.94 ; p=0.005)$, with an approximate doubling of the number of transneuronally infected PVN neurons between P4/P6 and P8/P10 (Table 1, Fig. 5). Age-related differences were documented in the dorsal $(p=0.032)$, medial $(p<0.001)$, and posterior $(p=0.003)$ parvocellular subregions, but not in the anterior parvocellular subregion ( $p=0.177$ ) (Fig. 5).

\section{CeA and BNST}

PRV labeling was consistently observed in the medial CeA and dorsolateral BNST in control NH/NS rat pups from both age groups (Figs. 4, 6). Strikingly, however, the number of transneuronally infected neurons within the medial CeA, lateral CeA, and BNST increased by 20-, 30-, and 40-fold, respectively, between P4/P6 and P8/P10 (Table 1, Fig. 6). ANCOVA confirmed the presence of significant age-related increases in the number of transneuronally infected neurons within the medial CeA $\left(F_{(1,8)}=\right.$ 65.04; $p<0.001)$, lateral CeA $\left(F_{(1,8)}=33.26 ; p=0.001\right)$, and $\operatorname{BNST}\left(F_{(1,8)}=303.77 ; p<0.001\right)$ (Table 1, Fig. 6).

\section{Visceral cortex}

The cortex did not contain PRV-positive neurons in any of the five control rats injected with virus on P4 and killed on P6 (data not shown). Conversely, the IN and IL/PL visceral cortices consistently contained PRV-positive neurons in all five control pups injected with virus on P8 and killed on P10 (Table 1, Fig. 7).

\section{Effect of neonatal handling and maternal separation on transneuronal forebrain infection}

As described above, results in NH/NS control rats from the P4/P6 and $\mathrm{P} 8 / \mathrm{P} 10$ age groups confirmed that the first $10 \mathrm{~d}$ of postnatal development are characterized by large and significant increases in the number of hypothalamic and limbic preautonomic neurons that become transneuronally infected after PRV inoculation of the ventral stomach wall. The results described below summarize our principal findings regarding the effects of daily handling coupled with either $15 \mathrm{~min}$ or $3 \mathrm{~h}$ maternal separation, beginning on $\mathrm{P} 1$, on the developmental assembly of hypothalamic and limbic preautonomic circuits. Figure 8 illustrates representative examples of the extent of labeling observed in the PVN, BNST, and $\mathrm{CeA}$ in control rat pups and in H/S pups.
Effect of handling/maternal separation on body weight growth ANOVA revealed no significant effect of treatment group (i.e., $\mathrm{NH} / \mathrm{NS}$ control, $15 \mathrm{~min} \mathrm{H} / \mathrm{S}$, or $3 \mathrm{~h} \mathrm{H} / \mathrm{S}$ ) on pup body weights measured just before virus injection surgery on $\mathrm{P} 8\left(F_{(2,16)}=2.60\right.$; $p=0.109)$. Body weights averaged $20.54 \pm 0.36 \mathrm{~g}$ in the NH/NS control group, $19.93 \pm 1.02 \mathrm{~g}$ in the $15 \mathrm{~min} \mathrm{H} / \mathrm{S}$ group, and $22.09 \pm 0.48 \mathrm{~g}$ in the $3 \mathrm{~h} \mathrm{H} / \mathrm{S}$ group.

\section{PVN}

ANCOVA revealed no significant effect of treatment group on the total number of transneuronally infected PVN neurons in pups injected with virus on P8 and killed 63-66 h later, on P10 $\left(F_{(2,19)}=3.308 ; p=0.061\right)$ (Table 1$)$. However, additional analysis revealed a small but significant effect of treatment on the number of PRV-positive neurons within the posterior parvocellular subdivision of the $\operatorname{PVN}\left(F_{(2,19)}=4.010 ; p=0.035\right)$. Post hoc $t$ tests confirmed that fewer infected neurons were present in the posterior subdivision in pups from the $15 \mathrm{~min} \mathrm{H} / \mathrm{S}$ treatment group compared with transneuronal labeling in age-matched NH/NS controls (Fig. 5). Other between-group differences in posterior parvocellular cell counts were not significant. Similar analyses failed to reveal any significant effect of treatment group on the number of PRV-immunopositive neurons within the anterior $\left(F_{(2,19)}=0.056 ; p=0.946\right)$, dorsal $\left(F_{(2,19)}=3.363 ; p=\right.$ $0.059)$, or medial $\left(F_{(2,19)}=0.146 ; p=0.866\right)$ parvocellular PVN subdivisions (Fig. 5). The data suggest a relatively minor and highly localized effect of postnatal handling on a subset of PVN neurons projecting to preautonomic brainstem nuclei.

\section{CeA and BNST}

ANCOVA revealed a significant effect of treatment group on transneuronal labeling within both the medial CeA $\left(F_{(2,19)}=\right.$ 328.132; $p<0.001)$ and the lateral CeA $\left(F_{(2,19)}=138.741 ; p<\right.$ 0.001 ) in P8/P10 pups (Table 1). Post hoc $t$ tests confirmed that both CeA subdivisions contained fewer PRV-immunopositive neurons in pups from the $15 \mathrm{~min}$ and $3 \mathrm{~h} \mathrm{H} / \mathrm{S}$ treatment groups compared with age-matched NH/NS controls (Table 1, Fig. 6); however, cell counts did not differ significantly between $15 \mathrm{~min}$ $\mathrm{H} / \mathrm{S}$ and $3 \mathrm{~h} \mathrm{H} / \mathrm{S}$ groups. ANCOVA revealed a similar overall effect of treatment on BNST transneuronal labeling $\left(F_{(2,19)}=\right.$ $10.973 ; p=0.001)$. Post hoc $t$ tests confirmed the presence of fewer infected BNST neurons in both $15 \mathrm{~min}$ and $3 \mathrm{~h} \mathrm{H} / \mathrm{S}$ groups compared with age-matched NH/NS controls, but no significant difference between the $15 \mathrm{~min}$ and $3 \mathrm{~h}$ treatment groups (Table 1, Fig. 6). The data suggest a robust and distributed effect of postnatal handling on basal forebrain neurons projecting to preautonomic brainstem nuclei.

\section{Visceral cortices}

ANCOVA revealed a significant effect of treatment on transneuronal labeling within the IL/PL visceral cortex $\left(F_{(2,19)}=82.23\right.$; $p<0.001)$ in $\mathrm{P} 8 / \mathrm{P} 10$ pups. Post hoc $t$ tests demonstrated a significant reduction of IL/PL labeling in pups from the $15 \mathrm{~min} \mathrm{H/S}$ treatment group compared with age-matched $\mathrm{NH} / \mathrm{NS}$ controls (Table 1, Fig. 7). Other between-group differences in IL/PL labeling were not significant, despite a trend toward reduced labeling in the $3 \mathrm{~h} \mathrm{H} / \mathrm{S}$ group compared with controls (Table 1, Fig. 7). There also was no significant effect of treatment group on transneuronal labeling within the IN cortex $\left(F_{(2,19)}=1.667 ; p=\right.$ $0.218)$, despite an apparent trend toward reduced numbers of transneuronally infected IN neurons in both the $15 \mathrm{~min}$ and $3 \mathrm{~h}$ $\mathrm{H} / \mathrm{S}$ treatment groups compared with age-matched NH/NS controls (Table 1, Fig. 7). 

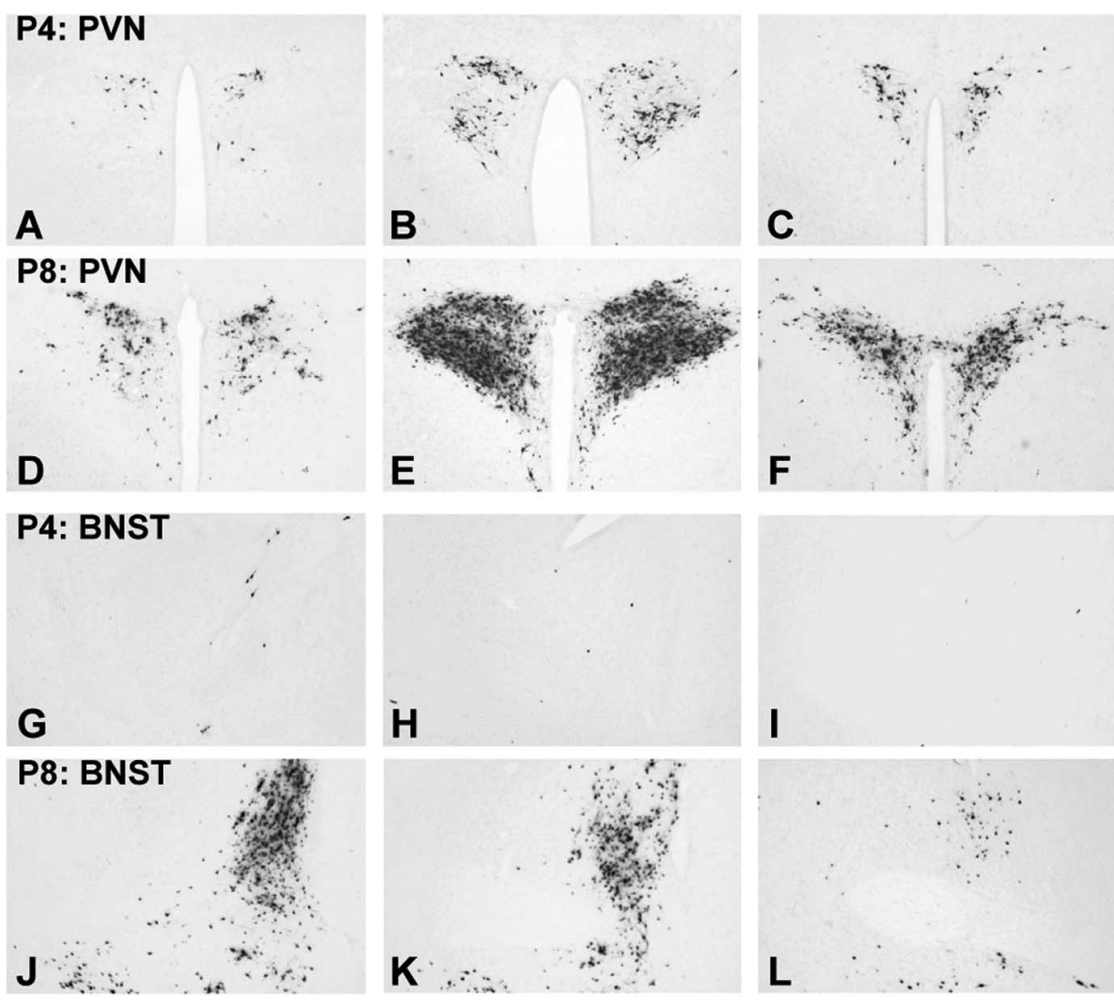

\section{P4: Ce Amygdala}
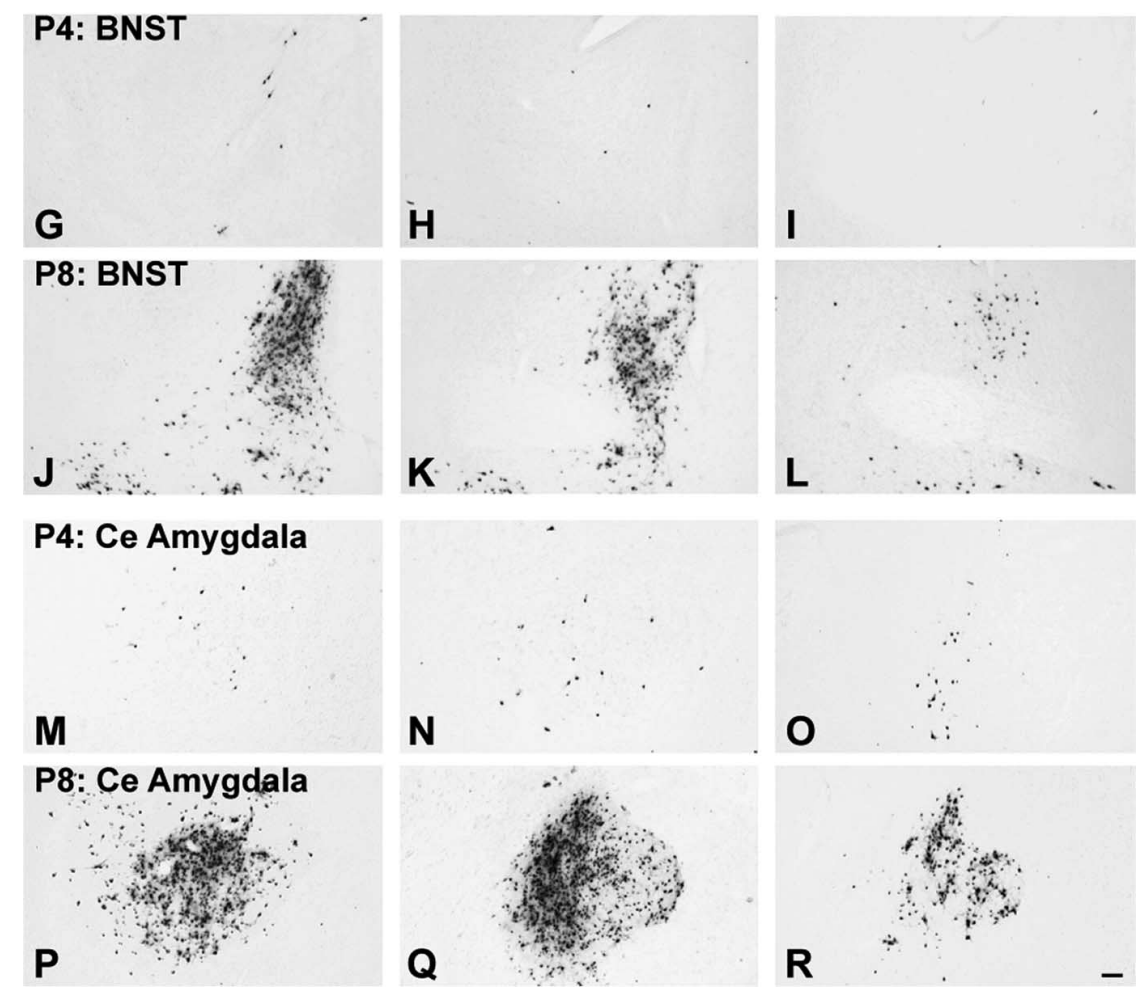

Figure 4. Age-dependent assembly of preautonomic circuits. Large numbers of transneuronally infected neurons are evident in the PVN $(\boldsymbol{D}-\boldsymbol{F})$, BNST $(\boldsymbol{J}-\boldsymbol{L})$, and CeA $(\boldsymbol{P}-\boldsymbol{R})$ in control NH/NS rat pups injected with virus on P8 and killed on P10; evidence that these synaptic inputs from neurons in these regions to gastric autonomic output neurons are well established by this time. In contrast, significantly fewer infected neurons are evident within the PVN $(\boldsymbol{A}-\boldsymbol{C})$, BNST $(\mathbf{G}-\boldsymbol{I})$, or CeA (M-0) in $\mathrm{NH} / \mathrm{NS}$ rat pups injected with virus on $\mathrm{P} 4$ and killed on $\mathrm{P} 6$, despite comparable infection within the hindbrain DVC in all cases (see also Fig. 3). Each row of photomicrographs depicts sections through rostral (left), intermediate (middle), and caudal (right) levels through each region. Scale bar: (in $\boldsymbol{R}) \boldsymbol{A}-\boldsymbol{R}, 100 \mu \mathrm{m}$. See Figure 1 for regional schematics.

\section{Discussion}

Integrated autonomic responses to emotional stimuli depend on direct and relayed neural projections from the hypothalamus and limbic forebrain to autonomic motor neurons (Jordan, 1990; LeDoux, 1996). The outcome of transneuronal PRV tracing in control rat pups examined at $\mathrm{P} 4 / \mathrm{P} 6$ or P8/P10 indicates that the first 10 postnatal days are marked by significant maturation of these circuits, consistent with our previous reports (Rinaman et al., 1999, 2000). Thus, this early developmental window represents a potential "sensitive period" during which experience can influence the ongoing assembly of central circuits that modulate autonomic emotional motor outflow.

\section{Postnatal circuit development and early experience}

Our previous work demonstrated that PRV transneuronal transport is a sensitive measure of emerging synaptic interac- tions that are distinct from the nonsynaptic invasion of afferent fibers into a target nucleus (Rinaman et al., 2000). The present findings extend those results by including (1) a thorough subregional quantitative analysis of the progressive recruitment of PVN, CeA, BNST, and visceral cortical neurons into central autonomic circuits during a brief developmental window that is marked by significant increases in neural circuit connectivity, and (2) a demonstration that the extent of transneuronal forebrain infection is correlated with transneuronal infection of medullary AP neurons in $\mathrm{NH} / \mathrm{NS}$ control rats.

The most exciting result from this study is that daily handling of rat pups, coupled with either brief or extended periods (i.e., $15 \mathrm{~min}$ or $3 \mathrm{~h}$ ) of maternal separation, beginning on P1, significantly reduces the number of preautonomic limbic forebrain neurons infected by transneuronal viral transport from the stomach, as assayed between P8 and P10. This result was unrelated to any effect of H/S on overall body growth; thus, it strongly implicates an experience-dependent effect on the developmental assembly of central neural circuits. The significant reduction in transneuronal infection of limbic cell groups also cannot be attributed to a general treatment-related suppression of PRV replication and/or transport, because in the same animals there was little or no effect of $\mathrm{H} / \mathrm{S}$ on transneuronal viral transport to the parvocellular PVN. Instead, these results are consistent with an experience-induced alteration of the assembly of specific limbic and cortical preautonomic circuits that normally undergo large-scale increases in synaptic connectivity during the same postnatal period. The apparent lack of treatment-related effects on the distribution and density of transneuronal infection within the PVN and within autonomic and preautonomic brainstem nuclei is consistent with evidence presented previously (Rinaman et al., 1999, 2000) and confirmed in this study, that these circuits are established earlier during development than the limbic and cortical circuits. The earlier assembly of brainstem and hypothalamic circuits may render them less susceptible to significant modification as a result of the early H/S manipulations used here.

It is not clear why the $15 \mathrm{~min}$ and $3 \mathrm{~h} \mathrm{H} / \mathrm{S}$ manipulations produced equivalent reductions in limbic forebrain transneuronal viral transport. Previous work using similar H/S paradigms revealed reliable differences in certain behavioral, molecular, and physiological parameters between adult rats that were daily handled and separated from their dam for either $15 \mathrm{~min}$ or $3 \mathrm{~h}$ during early postnatal life (Plotsky and Meaney, 1993; Francis et al., 1999; McIntosh et al., 1999; Ladd et al., 2000; Meaney, 2001; McNamara et al., 2002). However, those studies also report some $\mathrm{H} / \mathrm{S}$-related effects that were of similar magnitude and direction 


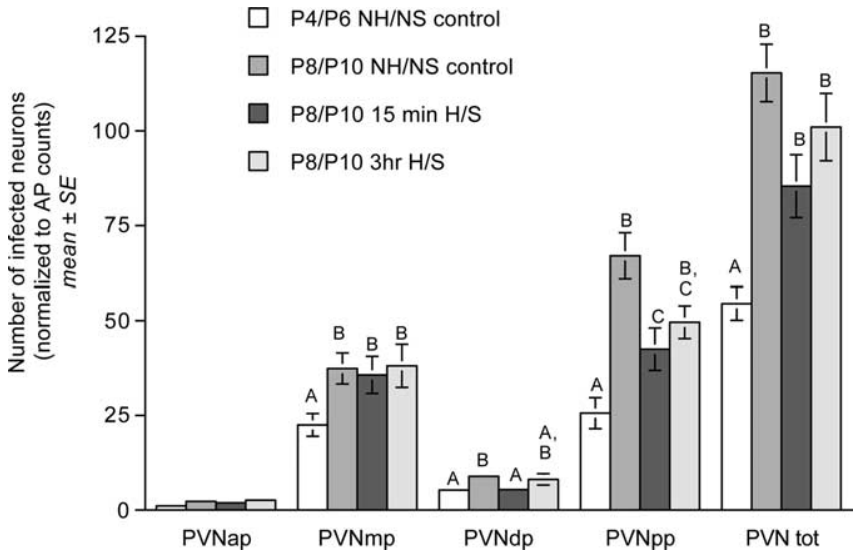

Figure 5. Bar graphs illustrating transneuronal infection of PVN neurons (normalized to AP infection within each case) in control NH/NS rat pups injected with virus on P4 or P8 and killed on $\mathrm{P} 6$ or $\mathrm{P} 10$, respectively, and in 15 min and $3 \mathrm{~h} \mathrm{H} / \mathrm{S}$ rat pups injected with virus on $\mathrm{P} 8$ and killed on P10 (group mean \pm SE). Bars represent labeling within four parvocellular PVN subnuclei, the anterior parvocellular (PVNap), medial parvocellular (PVNmp), dorsal parvocellular (PVNdp), and posterior parvocellular (PVNpp). The final set of bars represents total PVN (PVN tot). Within each subregion, bars with different letters (i.e., A, B, or C) are significantly different $(p<0.05$ ). Statistical comparisons were performed on log-transformed data that met assumptions of normality and homoscedasticity (see Results).

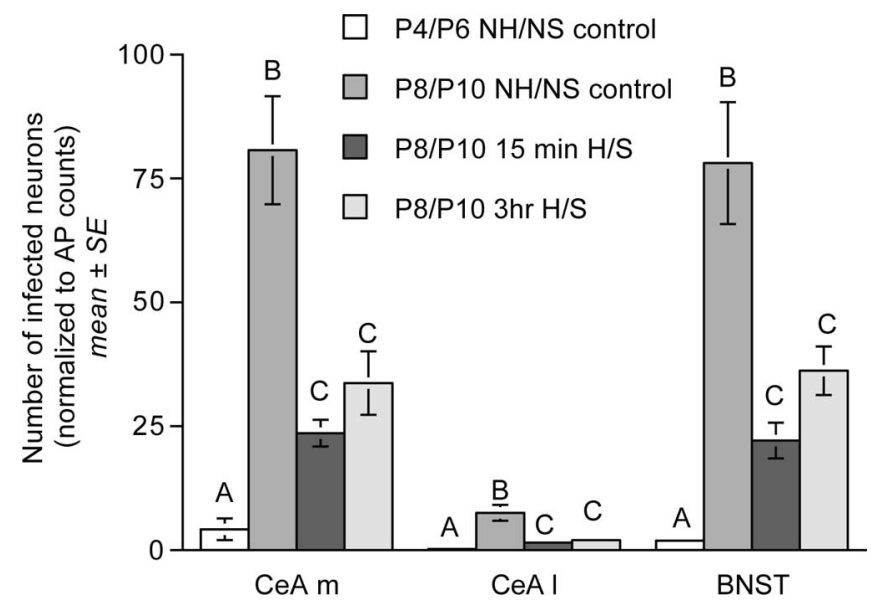

Figure 6. Bar graphs illustrating transneuronal infection of CeA [medial (CeA m) and lateral (CeA I) subnuclei] and BNST neurons (normalized to AP infection within each case) in control $\mathrm{NH} / \mathrm{NS}$ rat pups injected with virus on $\mathrm{P} 4$ or $\mathrm{P} 8$ and killed on $\mathrm{P} 6$ or $\mathrm{P} 10$, respectively, and in 15 $\min$ and $3 \mathrm{hH} / \mathrm{S}$ rat pups injected with virus on $\mathrm{P} 8$ and killed on $\mathrm{P} 10$ (group mean $\pm \mathrm{SE}$ ). Within each region, bars with different letters (i.e., $A, B$, or $C$ ) are significantly different $(p<0.05)$. Statistical comparisons were performed on log-transformed data that met assumptions of normality and homoscedasticity (see Results).

in both $15 \mathrm{~min}$ and $3 \mathrm{~h} \mathrm{H} / \mathrm{S}$ rats. It is important to emphasize that our neuroanatomical analyses were limited to a single early time point (i.e., P8/P10) within the ongoing development of the circuits under study. It will be of considerable interest to determine whether these experience-induced alterations in circuit assembly are associated with long-lasting alterations of autonomic emotional motor circuit connectivity in adult animals.

\section{PRV infection and circuit development}

The results reported here raise several intriguing questions that will require additional studies to address. First, we do not yet know whether the reduced transneuronal viral labeling observed at $\mathrm{P} 8 / \mathrm{P} 10$ represents merely a temporal delay in neural circuit development, or a persistent reduction in connec-

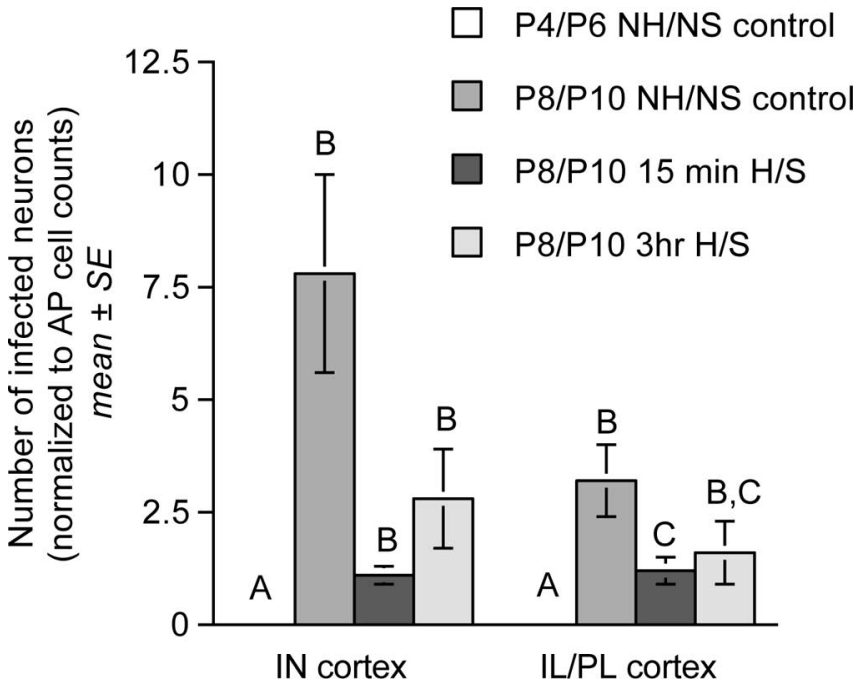

Figure 7. Bar graphs illustrating transneuronal infection of neurons within the IN and IL/PL medial prefrontal cortices (normalized to AP infection within each case) in control NH/NS rat pups injected with virus on P4 or P8 and killed on P6 or P10, respectively, and in 15 min and $3 \mathrm{~h}$ $\mathrm{H} / \mathrm{S}$ rat pups injected with virus on $\mathrm{P} 8$ and killed on $\mathrm{P} 10$ (group mean $\pm \mathrm{SE}$ ). Within each region, bars with different letters (i.e., A, B, or C) are significantly different $(p<0.05)$. Statistical comparisons were performed on log-transformed data that met assumptions of normality and homoscedasticity (see Results).

tivity. We also do not know whether reduced viral transport reflects a smaller number of forebrain neurons in synaptic contact with autonomic target neurons, a reduction in number or activity of synaptic connections formed by each forebrain neuron with its autonomic target cell, or a reduction in the collateralization of descending projections that give rise to the synaptic terminal arbor. All of these factors could contribute to the observed reduction in transneuronal labeling, because successful replication of PRV within neurons requires achievement of a threshold of infecting virions (Card et al., 1999). Although the precise threshold that must be reached is unknown, the number of virions transported to the nucleus of a neuron appears to be directly related to the number of axon terminals available for virion invasion, as well as the length of the axon through which the viral capsids must be transported retrogradely before they can contribute to viral replication in the nucleus. The apparently normal course of PRV transneuronal infection of medial hypothalamic neurons argues against the idea that the H/S paradigms somehow altered rates of axonal transport of PRV. Instead, our findings support the conclusion that postnatal $\mathrm{H} / \mathrm{S}$ reduced the number of limbic and cortical preautonomic neurons and/or altered the postnatal assembly of their synaptic inputs to autonomic target cells.

A number of factors may account for the relatively large variability observed in the retrograde infection of visceral cortices in control pups assayed on P10. Anterograde neural tracing studies in adult rats have demonstrated that neurons within the infralimbic medial prefrontal cortex and a subregion of the agranular insular cortex project directly to the DVC, and also project to preautonomic subregions of the BNST and CeA (Saper, 1982; Terreberry and Neafsay, 1983, 1987; Hurley et al., 1991; Torrealba and Muller, 1996; Vertes, 2004). Thus, transneuronal viral infection of preautonomic cortical neurons may arise from both direct and polysynaptic central pathways. However, the kinetics of viral transport and replication, coupled with the relatively 


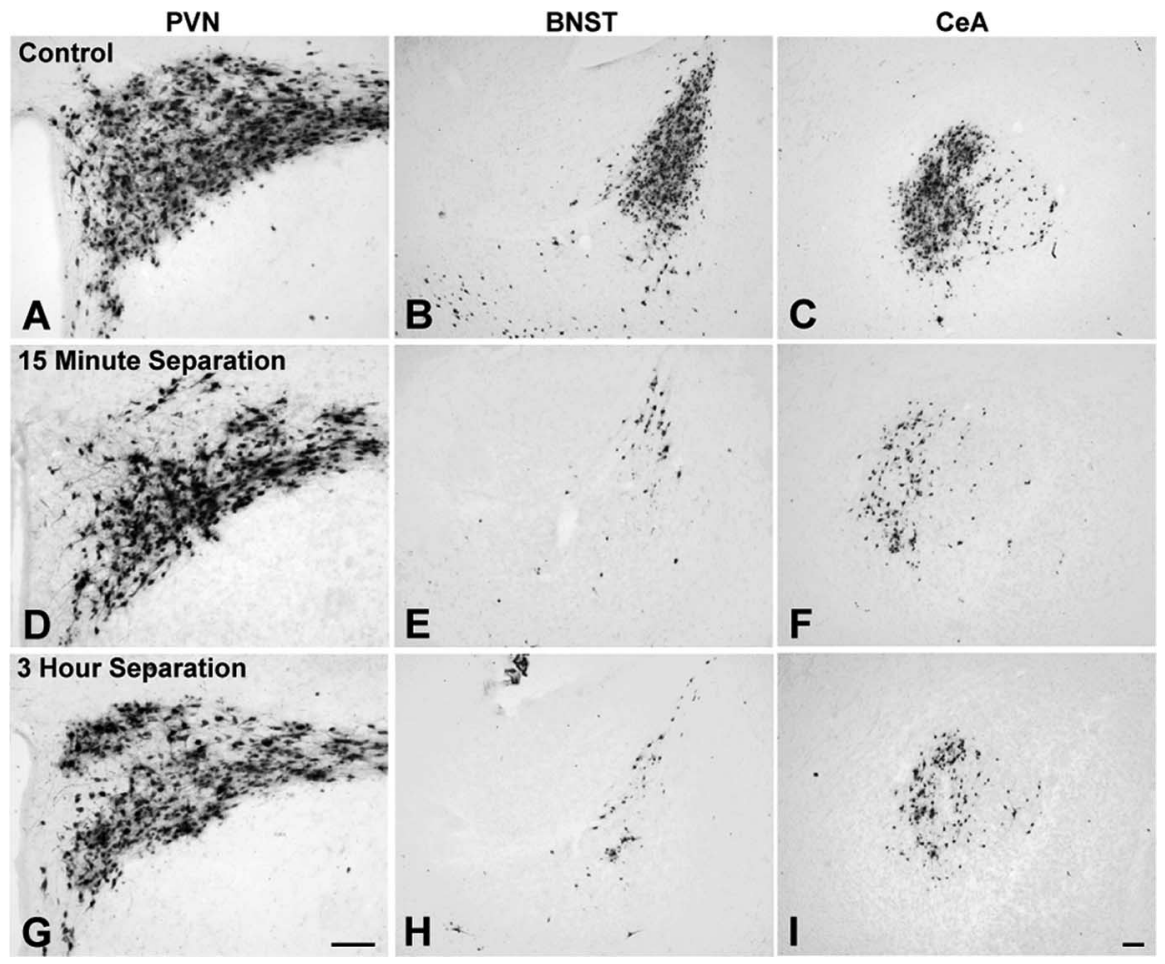

Figure 8. The effect of daily repeated postnatal $H / S$ on transneuronal infection of the PVN, BNST, and CeA is illustrated. Control $\mathrm{NH} / \mathrm{NS}$ rat pups injected with virus on P8 and killed on P10 exhibited robust infection within each forebrain region $(\boldsymbol{A}-\boldsymbol{C})$. There was no significant effect of treatment on PVN transneuronal infection $(\boldsymbol{A}, \boldsymbol{D}, \boldsymbol{G})$. In contrast, the BNST $(\boldsymbol{B}, \boldsymbol{E}, \boldsymbol{H})$ and $\boldsymbol{C e A}(\boldsymbol{C}, \boldsymbol{F}, \boldsymbol{I})$ exhibited significantly reduced transneuronal PRV labeling in $15 \mathrm{~min}$ and $3 \mathrm{hH} / \mathrm{S}$ rat pups. Scale bar: (in $\boldsymbol{I}) \boldsymbol{A}-\boldsymbol{I}, 100 \mu \mathrm{m}$. See Figure 1 for regional schematics.

short postinoculation interval used in this study, support the likelihood that cortical neurons in P10 rat pups were infected via their direct descending projections to gastric-related DVC neurons. The relatively high variability in the number of preautonomic cortical neurons infected in P10 control pups may reflect the relatively early status of the still-developing descending cortical projection pathways, the longer axons involved in these pathways, and/or more sparse terminal arbors of cortical inputs to the DVC relative to inputs derived from the PVN, CeA, or BNST. Although the variability in cortical labeling reduced statistical power, clear trends were apparent in treatment-related effects on IL/PL and IN circuit assembly. Regarding variability, it is also interesting that transneuronal labeling within the CeA and BNST was more variable in $\mathrm{NH} / \mathrm{NS}$ control P10 pups compared with labeling in pups from the $15 \mathrm{~min}$ and $3 \mathrm{~h} \mathrm{H} / \mathrm{S}$ groups. Individual differences in behavioral and neuroendocrine responses to stress in rats are, in part, derived from naturally occurring variations in maternal care (Ladd et al., 2000; Meaney, 2001). Therefore, it is possible that both $15 \mathrm{~min}$ and $3 \mathrm{~h} \mathrm{H} / \mathrm{S}$ paradigms served to reduce this natural variability.

\section{Functional implications of selective alterations in circuit development}

Autonomic responses to stimuli that elicit fear, anxiety, or other strong emotions typically include significant alterations of autonomic outflow, including gastrointestinal function (Kaplan et al., 1996; Punyabati et al., 2000; Mayer et al., 2001). The PVN, CeA, BNST, and IN and IL/PL cortices serve as principal gateways for septohippocampal and cortical influences over autonomic components of emotional motor responses (Pratt, 1992; Phillips and LeDoux, 1994; LeDoux, 1996; Vouimba et al., 1998). In rats, the large majority of these preautonomic forebrain neurons first establish synaptic connections with hindbrain and spinal autonomic neurons after birth. Consistent with our previous work (Rinaman et al., 2000), the present results demonstrate that the PVN becomes integrated into preautonomic circuits relatively early, whereas the CeA, BNST, and visceral cortices become integrated at progressively later time points.

The PVN is a phenotypically and functionally heterogeneous nucleus. In this regard, it is interesting that one subregion of the PVN, the posterior parvocellular, displayed a small but statistically significant treatment-related reduction in transneuronal viral labeling in the present study. This posterior subdivision demonstrated the largest increase in viral transneuronal labeling of all four parvocellular subdivisions between P4/P6 and P8/P10 in control NH/NS rat pups, evidence that a significant amount of synaptic connectivity normally emerges between posterior parvocellular PVN neurons and gastricrelated autonomic neurons within that time frame, and perhaps accounting for the observed treatment-related plasticity within that circuit. It will be important to determine whether the experience-dependent changes in the assembly of emotional motor circuits demonstrated in the present study are similarly restricted to effects exerted during the first postnatal week and, more importantly, whether these changes represent a permanent modification of the system as has been demonstrated for the hypothalamic-pituitary-adrenal axis and for behavioral responses to stressful and emotionally evocative stimuli (Plotsky and Meaney, 1993; Francis et al., 1999; Ladd et al., 2000; Meaney, 2001).

The CeA and BNST are strongly implicated in autonomic components of fear and anxiety (LeDoux et al., 1988; Davis, 1998), and direct descending projections from the CeA and BNST to the DVC represent pathways for the regulation of gastrointestinal and other autonomic functions by telencephalic structures (Berntson et al., 1998). The visceral cortices, similarly, are implicated in autonomic reactivity associated with anxiety and other affective states (LeDoux, 1996; Price, 1999), and stimulation of either the IN or IL/PL cortex produces an inhibition of gastrointestinal activity similar to that produced by exposure to fear-inducing stimuli (Aleksandrov et al., 1996; Yamamoto and Sawa, 2000). Although afferents from CeA and BNST neurons reach the DVC within a day after birth, they do not begin to establish synaptic connections with gastric-related DVC neurons until approximately P4-P6 (Rinaman et al., 2000). Cortical inputs to the DVC do not arrive until a day or two after the arrival of inputs from the CeA and BNST, and cortical inputs do not establish synaptic contacts with DVC neurons until some time after P6 (Rinaman et al., 2000). The present results suggest that, in contrast 
to the PVN circuits, all of the relatively late-developing components of central autonomic circuits exhibit plasticity in response to significant postnatal epigenetic events.

In conclusion, these data demonstrate alterations in the developmental trajectory of synaptic circuits caused by neonatal handling and maternal separation. The degree to which these early changes in circuit architecture persist into later life are not yet known; however, the observed changes in circuitry involve regions of the neuraxis that contribute importantly to the central neural control of autonomic emotional motor responses and that appear to be sensitive to environmental influences exerted during early postnatal development.

\section{References}

Aleksandrov VG, Bagaev VA, Nozdrachev AD, Panteleev SS (1996) Identification of gastric related neurones in the rat insular cortex. Neurosci Lett 216:5-8.

Andersen SL (2003) Trajectories of brain development: point of vulnerability or window of opportunity? Neurosci Biobehav Rev 27:3-18.

Armstrong WE, Warach S, Hatton GI, McNeill TH (1980) Subnuclei in the rat hypothalamic paraventricular nucleus: a cytoarchitectural, horseradish peroxidase and immunocytochemical analysis. Neuroscience 5:1931-1958.

Bartha A (1961) Experimental reduction of virulence of Aujeszky's disease virus. Magy Allotorv Lapja 16:42-45.

Bence M, Levelt CN (2005) Structural plasticity in the developing visual system. Prog Brain Res 147:125-139.

Berntson GG, Sarter M, Cacioppo JT (1998) Anxiety and cardiovascular reactivity: the basal forebrain cholinergic link. Behav Brain Res 94:225-248.

Braunewell KH, Manahan-Vaughan D (2001) Long-term depression: a cellular basis for learning? Rev Neurosci 12:121-140.

Card JP, Enquist LW, Moore RY (1999) Neuroinvasiveness of pseudorabies virus injected intracerebrally is dependent on viral concentration and terminal field density. J Comp Neurol 407:438-452.

Cassell MD, Gray TS, Kiss JZ (1986) Neuronal architecture in the rat central nucleus of the amygdala: a cytological, hodological, and immunocytochemical study. J Comp Neurol 246:478-499.

Champagne FA, Francis DD, Mar A, Meaney MJ (2003) Variations in maternal care in the rat as a mediating influence for the effects of environment on development. Physiol Behav 79:359-371.

Coutinho SV, Plotsky PM, Sablad M, Miller JC, Zhou H, Bayati AI, McRoberts JA, Mayer EA (2002) Neonatal maternal separation alters stressinduced responses to viscerosomatic nociceptive stimuli in rat. Am J Physiol 282:G307-G316.

Davis M (1998) Are different parts of the extended amygdala involved in fear versus anxiety? Biol Psychiatry 44:1239-1247.

Debanne D, Daoudal G, Sourdet V, Russier M (2003) Brain plasticity and ion channels. J Physiol (Paris) 97:403-414.

Fox K (2002) Anatomical pathways and molecular mechanisms for plasticity in the barrel cortex. Neuroscience 111:799-814.

Francis DD, Caldji C, Champagne F, Plotsky PM, Meaney MJ (1999) The role of corticotropin-releasing factor-norepinephrine systems in mediating the effects of early experience on the development of behavioral and endocrine responses to stress. Biol Psychiatry 46:1153-1166.

Hebb DO (1949) The organization of behavior: a neuropsychological theory. New York: Wiley.

Heim C, Nemeroff CB (2001) The role of childhood trauma in the neurobiology of mood and anxiety disorders: preclinical and clinical findings. Biol Psychiatry 49:1023-1039.

Hurley KM, Herbert H, Moga MM, Saper CB (1991) Efferent projections of the infralimbic cortex of the rat. J Comp Neurol 308:249-276.

Jordan D (1990) Autonomic changes in affective behavior. In: Central regulation of autonomic functions (Loewy AD, Spyer KM, eds), pp 349-366. New York: Oxford UP.

Ju G, Swanson LW (1989) Studies on the cellular architecture of the bed nuclei of the stria terminalis in the rat: I. Cytoarchitecture. J Comp Neurol 280:587-602.
Ju G, Swanson LW, Simerly RB (1989) Studies on the cellular architecture of the bed nuclei of the stria terminalis in the rat: II. Chemoarchitecture. J Comp Neurol 280:603-621.

Kaplan DS, Masand PS, Gupta S (1996) The relationship of irritable bowel syndrome (IBS) and panic disorder. Ann Clin Psychiatry 8:81-88.

Kim JJ, Thompson RF (1997) Cerebellar circuits and synaptic mechanisms involved in classical eyeblink conditioning. Trends Neurosci 20:177-181.

Kiss JZ, Martos J, Palkovits M (1991) Hypothalamic paraventricular nucleus: a quantitative analysis of cytoarchitectonic subdivisions in the rat. J Comp Neurol 313:563-573.

Ladd CO, Huot RL, Thrivikraman KV, Nemeroff CB, Meaney MJ, Plotsky PM (2000) Long-term behavioral and neuroendocrine adaptations to adverse early experience. Prog Brain Res 122:81-103.

LeDoux JE (1996) The emotional brain: the mysterious underpinnings of emotional life. New York: Simon and Schuster.

LeDoux JE, Iwata J, Cicchetti P, Reis DJ (1988) Different projections of the central amygdaloid nucleus mediate autonomic and behavioral correlates of conditioned fear. J Neurosci 8:2517-2529.

Mayer EA, Naliboff BD, Chang L, Coutinho SV (2001) V. Stress and irritable bowel syndrome. Am J Physiol 280:G519-G524.

McDonald AJ (1982) Cytoarchitecture of the central amygdaloid nucleus of the rat. J Comp Neurol 208:401-418.

McIntosh J, Anisman H, Merali Z (1999) Short- and long-periods of neonatal maternal separation differentially affect anxiety and feeding in adult rats: gender-dependent effects. Brain Res Dev Brain Res 113:97-106.

McNamara RK, Huot RL, Lenox R, Plotsky PM (2002) Postnatal maternal separation elevates the expression of the postsynaptic protein kinase $\mathrm{C}$ substrate RC3, but not presynaptic GAP-43, in developing rat hippocampus. Dev Neurosci 24:485-494.

Meaney MJ (2001) Maternal care, gene expression, and the transmission of individual differences in stress reactivity across generations. Annu Rev Neurosci 24:1161-1192.

Medina JF, Repa JC, Mauk MD, LeDoux JE (2002) Parallels between cerebellum- and amygdala-dependent conditioning. Nat Rev Neurosci 3:122-131.

Nakahara H, Zhang LI, Merzenich MM (2004) Specialization of primary auditory cortex processing by sound exposure in the "critical period." Proc Natl Acad Sci USA 101:7170-7174.

Phillips RG, LeDoux JE (1994) Lesions of the dorsal hippocampal formation interfere with background but not foreground contextual fear conditioning. Learn Mem 1:34-44.

Plotsky PM, Meaney MJ (1993) Early, postnatal experience alters hypothalamic corticotropin-releasing factor (CRF) mRNA, median eminence CRF content and stress-induced release in adult rats. Brain Res Mol Brain Res 18:195-200.

Pratt JA (1992) The neuroanatomical basis of anxiety. Pharmacol Ther 55:149-181.

Price JL (1999) Prefrontal cortical networks related to visceral function and mood. Ann NY Acad Sci 877:383-396.

Pryce CR, Bettschen D, Bahr NI, Feldon J (2001) Comparison of the effects of infant handling, isolation, and nonhandling on acoustic startle, prepulse inhibition, locomotion, and HPA activity in the adult rat. Behav Neurosci 115:71-83.

Punyabati O, Deepak KK, Sharma MP, Dwivedi SN (2000) Autonomic nervous system reactivity in irritable bowel syndrome. Indian J Gastroenterol 19:122-125.

Rinaman L, Roesch MR, Card JP (1999) Retrograde transynaptic pseudorabies virus infection of central autonomic circuits in neonatal rats. Brain Res Dev Brain Res 114:207-216.

Rinaman L, Levitt P, Card JP (2000) Progressive postnatal assembly of limbic-autonomic circuits revealed by central transneuronal transport of pseudorabies virus. J Neurosci 20:2731-2741.

Saper CB (1982) Convergence of autonomic and limbic connections in the insular cortex of the rat. J Comp Neurol 210:163-173.

Saper CB (2004) Central autonomic system. In: The rat nervous system (Paxinos G, ed), pp 761-796. Amsterdam: Elsevier Academic.

Shapiro RE, Miselis RR (1985) The central organization of the vagus nerve innervating the stomach of the rat. J Comp Neurol 238:473-488. 
Swanson LW (1998) Brain maps: structure of the rat brain, Ed 2. Amsterdam: Elsevier.

Swanson LW, Kuypers HG (1980) The paraventricular nucleus of the hypothalamus: cytoarchitectonic subdivisions and the organization of projections to the pituitary, dorsal vagal complex, and spinal cord as demonstrated by retrograde fluorescence double-labeling methods. J Comp Neurol 194:555-570.

Terreberry RR, Neafsay EJ (1983) Rat medial frontal cortex: a visceral motor region with a direct projection to the solitary nucleus. Brain Res 278:245-249.

Terreberry RR, Neafsey EJ (1987) The rat medial frontal cortex projects directly to autonomic regions of the brainstem. Brain Res Bull 19:639-649.

Torrealba F, Muller C (1996) Glutamate immunoreactivity of insular cortex afferents to the nucleus tractus solitarius in the rat: a quantitative electron microscopic study. Neuroscience 71:77-87.
Vertes RP (2004) Differential projections of the infralimbic and prelimbic cortex in the rat. Synapse 51:32-58.

Vouimba RM, Garcia R, Jaffard R (1998) Opposite effects of lateral septal LTP and lateral septal lesions on contextual fear conditioning in mice. Behav Neurosci 112:875-884.

Watson Jr RE, Wiegand SJ, Clough RW, Hoffman GE (1986) Use of cryoprotectant to maintain long-term peptide immunoreactivity and tissue morphology. Peptides 7:155-159.

Weaver IC, Cervoni N, Champagne FA, D’Alessio AC, Sharma S, Seckl JR, Dymov S, Szyf M, Meaney MJ (2004) Epigenetic programming by maternal behavior. Nat Neurosci 7:847-854.

Yamamoto T, Sawa K (2000) Comparison of c-fos-like immunoreactivity in the brainstem following intraoral and intragastric infusions of chemical solutions in rats. Brain Res 866:144-151. 